\title{
Queratosis actínica poscirugía de pterigión
}

\section{Actinic keratosis post pterygium surgery}

\author{
René Hernán Parada-Vásquez ${ }^{1 *}$, Juan Pablo Medina-López² y Agustín del Valle-Penella ${ }^{3}$ \\ ${ }^{1}$ Fellowship de segmento anterior; ${ }^{2}$ Residente de tercer año de Oftalmología; ${ }^{3}$ Residente de primer año de Oftalmología. Instituto de la visión, \\ Hospital La Carlota, Montemorelos, Nuevo León, México
}

Paciente femenino de 50 años de edad, que consulta por presentar molestias en el ojo izquierdo. Dentro de sus antecedentes, hace 8 meses se le realizó cirugía de pterigión en el ojo izquierdo. Mostró agudeza visual lejana, sin corrección en el ojo derecho: 20/20; y en el ojo izquierdo: 20/30. Al examen físico en el ojo izquierdo: se evalúan ducciones y versiones normales, sin restricción de movimientos oculares. Se observa la presencia de una lesión elevada, de bordes regulares, con aspecto de "granuloma» de $2 \times 3 \mathrm{~mm}$. De diámetro en conjuntiva bulbar (Fig. 1); la córnea se observa dentro de límites normales, así como el resto del segmento anterior. Se procede a realizar biopsia excisional. Al estudio microscópico se encuentra, epitelio plano estratificado no queratinizado (Fig. 2A), con áreas de acantosis (Fig. 2B), múltiples zonas de proliferación de epitelio superficial con queratinización (Figs. 2C y D), respetando la membrana basal, encontrando en el estroma cambios de degeneración elastótica, sin cambios displásicos. El diagnóstico es biopsia excisional conjuntival de queratosis actínica en el ojo izquierdo.

\section{Responsabilidades éticas}

Protección de personas y animales. Los autores declaran que para esta investigación no se han

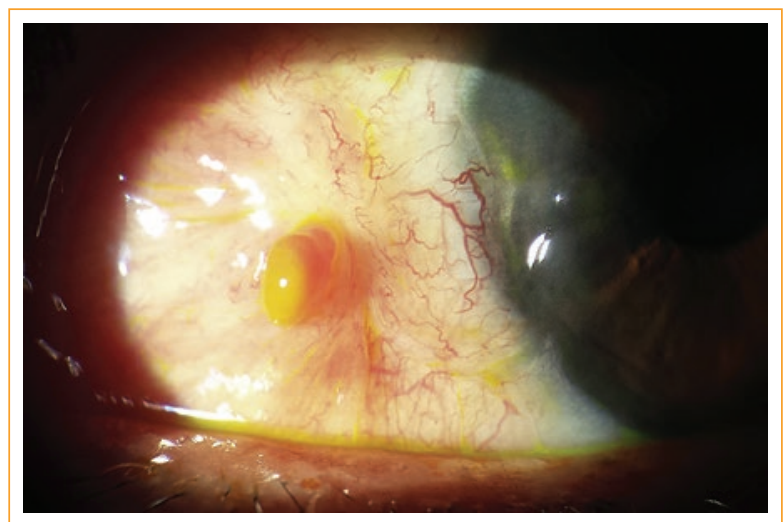

Figura 1. Lesión con características granulomatosas en conjuntiva bulbar poscirugía de pterigión.

realizado experimentos en seres humanos ni en animales.

Confidencialidad de los datos. Los autores declaran que ha seguido los protocolos de su centro de trabajo sobre la publicación de datos de pacientes.

Derecho a la privacidad y consentimiento informado. Los autores han obtenido el consentimiento informado de los pacientes y/o sujetos referidos en el artículo. Este documento obra en poder del autor de correspondencia.

\section{Correspondencia:}

*René Hernán Parada-Vásquez

Tabachin 10, Alamos 2 da sección Queretaro, Fecha de recepción: 30-07-2016 C.P. 76160, México

E-mail: rene_hernan@hotmail.com
Disponible en internet: 28-09-2016 Rev Mex Oftalmol. 2018;92(5):269-270 www.rmo.com.mx 


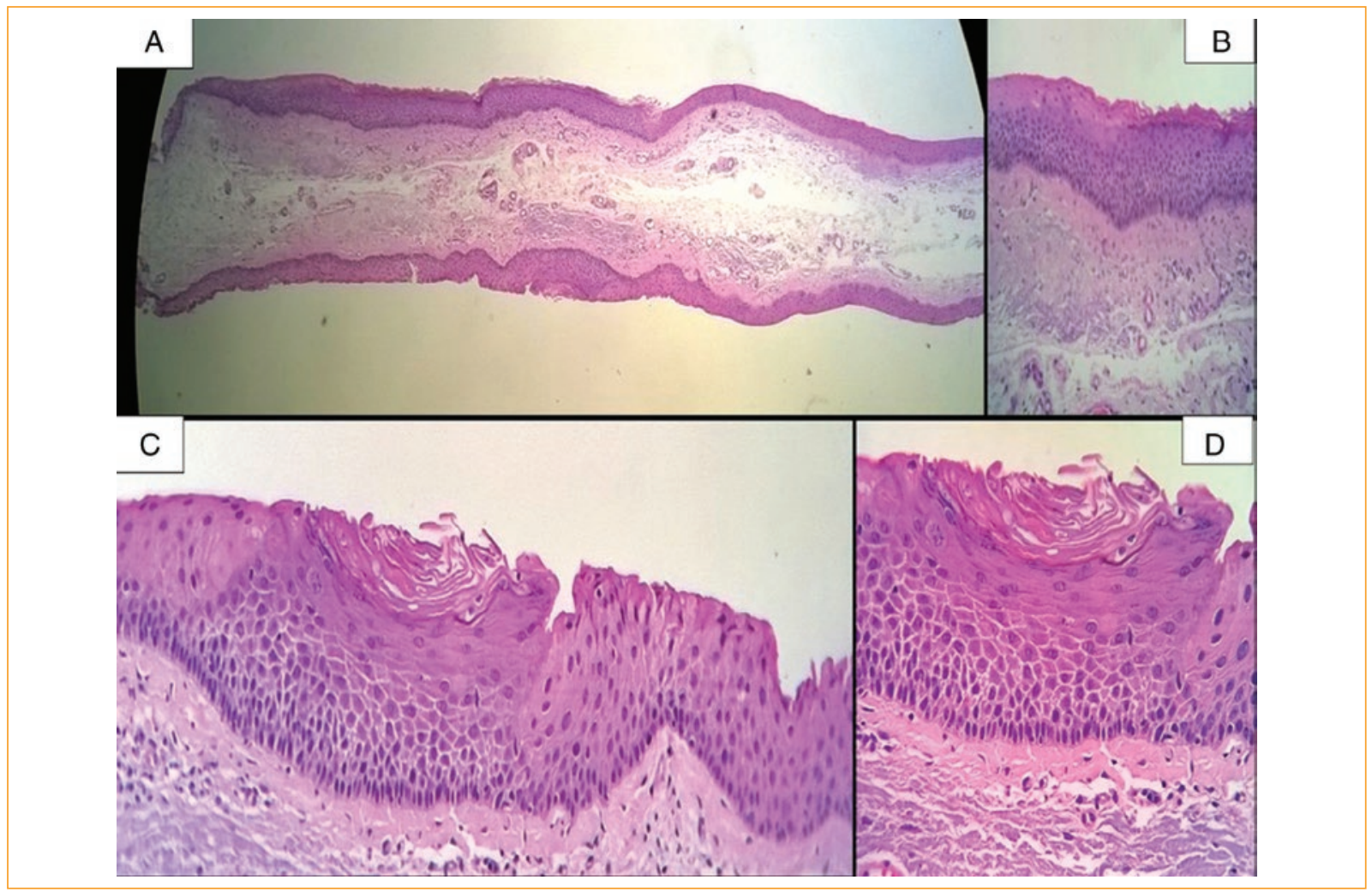

Figura 2. Biopsia de excisión conjuntival. A: Epitelio plano estratificado no queratinizado, con áreas de acantosis. B: múltiples zonas de proliferación de epitelio superficial con queratinización (C y D), respetando la membrana basal, y presentando cambios de degeneración elastótica en el estroma.

\section{Financiamiento}

Los autores no recibieron patrocinio para llevar a cabo este artículo.

\section{Conflicto de intereses}

Los autores declaran no tener ningún conflicto de intereses. 